the committee's unbridled enthusiasm for community psychiatric nursing services:

the Health Authority should expedite the expansion of the CPN Service in Harrow';

'an increase of two CPNs per year should be planned';

' 210 clients are currently supported by CPNs in Harrow. The service is clearly an important factor in the development of community services'.

The evidence on which these views were based is not stated and none of these recommendations or statements of opinion was placed in the context of other information about the management of patients within the unit. The 210 patients being supported by eight fulltime CPNs may be compared with the lists of over 200 patients that at least two consultants carry in their out-patient clinics. One might ask such questions as what type of patient is being seen in the two services? What is the overlap? What decisions are taken by the two services? What is the most cost effective way of preventing relapse and readmission? The HAS Committee recommendations ride roughshod over these issues. Community nursing services are good, psychiatrist-run outpatient clinics are bad.

Most distressing was the apparently complete lack of interest of the HAS team in serious clinical research. Such minor references to work at Northwick Park as appear in their report are mostly disparaging and it seemed that any appeal for evidence to substantiate particular opinions was regarded as a challenge to their right to issue authoritarian judgements on how a psychiatric service must be organised. We too protested individually and in considerable detail about aspects of the report, but these criticisms were brushed aside by the Director of the HAS.

The problem is one of excessive bureaucracy and centralisation. Because the remit of the HAS is so ill-defined and because the recommendations of the HAS have statutory force, power and influence over the psychiatric services have been concentrated in a few hands. Even if those involved were all well informed about the scope and limits of psychiatric knowledge this state of affairs would be undesirable.

In our opinion it would be much better that the HAS should be abolished than that it should continue in its present cumbersome and potentially destructive form. If it is to continue at all its remit should be restricted to identifying and correcting palpable psychiatric malpractices. It appears that this could be achieved with less contention, and considerably less expense, than is involved in the HAS system as it now operates.

T. J. Crow M. W. P. CARNEY EVE C. JOHNSTONE

Clinical Research Centre

Division of Psychiatry

Watford Road

Harrow, Middlesex

See page 145

\section{British psychiatrists in Canada} DEAR SIRS

When I read G. M. Green's article about British psychiatrists in Canada (Bulletin, April 1985, 9, 77-78) I thought it covered the topic well and was therefore surprised when I read Ishrat Ali's letter (Bulletin, December 1985, 9, 251). Because of my interest in the subject, I thought it only fair to give you another opinion of the situation.

It should be pointed out to any psychiatrist considering a move to Canada that Health Delivery is a Provincial, not a Federal, responsibility in Canada and what can be offered by one Province may not be available in another.

If a psychiatrist intends to emigrate to Canada and have a non-restrictive practice, he will require the LMCC and the $\operatorname{FRCP}(C)$ within a given period. However without these qualifications restrictions on practice do not always place the psychiatrist in a hospital remote from big cities with the higher cost of living inferred by Ishrat Ali.

With respect to emigrating to the Province of Alberta, I would suggest any psychiatrist considering the move first to secure a locum contract and experience the change of life style and professional practice. To be able to secure a contract it would be necessary for the psychiatrist to obtain a special licence from the Alberta College of Physicians and Surgeons and this would enable him to work within the terms of the contract.

During the contract period he should obtain from the Canadian College of Physicians and Surgeons what additional training is required to obtain the Canadian qualifications and also discuss with the appropriate schools of medicine how these could be obtained. Then with all this information make a decision on whether or not to emigrate.

It is difficult to assess what financial gain the psychiatrists would experience. Not having lived in England for several years, I'm not aware of the cost of living, but from the comments of a locum psychiatrist at present working with us, the cost of living in this area is comparable to England and the Canadian fee schedule much more attractive.

Should any of your readers require further information, I would be pleased to provide relevant data with respect to the Province of Alberta.

\section{Regional Director Alberta Social Services and Community Health 2105-20 Avenue \\ P.O. Box 60, Coaldale \\ Alberta, Canada}

ADIN StafFord

\section{DeAr SIRS}

I feel that Dr Ishrat Ali paints too gloomy a picture. For one accepted as fully trained the pay is now about twice the $\$ 70,000$ (Canadian) that he gives. The work is rewarding in 